\title{
Yiyecek İçecek İşletmelerinde Çalışanların Yönetici Koçluk Davranışı Algısının İş Tatmini Üzerindeki Etkisi
}

\author{
Erhan KILINÇ ${ }^{1}$, Fatih VAROL ${ }^{2}$ ve Rabia SAMUR ${ }^{3}$
}

$\ddot{O} z$

Yönetici koçluk davranışı, çalışanların performanslarını üst düzeye ulaştırmak, iş görenlerin kendi güçlü yönlerinin daha fazla farkına varmasını ve gerçek kapasitesini ortaya çıkarmasını sağlamak amacıyla yöneticilerin sergilediği motive edici, yönlendirici, tarafsız ve nesnel bir stratejik ortaklık davranışıdır. İş tatmini ise çalışanların işine, işyerine, iş çevresine karşı duyduğu, olumlu, rahatlatıcı ve huzur verici bir duygu yelpazesidir. Bu çalışmanın amacı yiyecek içecek işletmelerinde çalışanların yönetici koçluk davranışının iş tatmini üzerindeki etkisinin saptanmasıdır. Bu kapsamda Konya ilinde faaliyet gösteren kafelerde çalışanlar üzerinde anket uygulanmıştır. Araştırma kapsamında sosyo-demografik değişkenleri açısından yönetici koçluk davranışının ve çalışan iş tatminin farklılık gösterip göstermediği de ortaya konmaya çalışılmıştır. Araştırma sonuçlarına göre, çalışanların yönetici koçluk davranışı algılarının iş tatmini üzerinde pozitif ve anlamlı bir etkiye sahip olduğu görülmektedir. Yönetici koçluk davranışının iş tatmininin \%19,5'lik kısmını açıkladığını saptanmışır. Yönetici koçluğun iş görenlerin iş tatmini üzerinde pekiştirici etkisini ortaya koyan bu çalışma, örgütlerde bu davranış türünün diğer davranış ölçüt değişkenleri ile ilişkisini ve etkisini koyacak ve farklı örneklemlerde gerçekleşecek diğer çalışmaları yol gösterici niteliktedir.

Anabtar Kelimeler: Yiyecek içecek işletmeleri, Yönetici koçluk davranışı, İş tatmini, Kafe işletmeleri

\section{The Effect of Employees' Perception of Executive Coaching Behavior on Job Satisfaction} in Food and Beverage Businesses

\begin{abstract}
Executive coaching behavior is a motivating, directing, objective and objective strategic partnership behavior that managers exhibit in order to maximize employee performance and enable employees to become more aware of their own strengths and reveal their real capacity. Job satisfaction is a range of positive, relaxing and peaceful emotions that employees feel towards their work, workplace and work environment. The aim of this study is to determine the effect of executive coaching behavior of employees in food and beverage businesses on job satisfaction. In this context, a questionnaire was applied to the employees working in cafes operating in Konya. Within the scope of the research, it was also tried to find out whether executive coaching behavior and employee job satisfaction differ in terms of socio-demographic variables. According to the results of the research, it is seen that the employees' perceptions of executive coaching behavior have a positive and significant effect on job satisfaction. It has been determined that executive coaching behavior explains $19.5 \%$ of job satisfaction. The study, which shows the reinforcing effect of executive coaching on the job satisfaction of the employees, is a guiding feature in the organizations that will put the relationship and effect of this behavior type with other behavioral criteria variables and take place in different samples.
\end{abstract}

Key Words: Food and beverage businesses, Executive coaching behavior, Job satisfaction, Cafe businesses

\section{Atıf İçin / Please Cite As:}

Kılınç, E., Varol. F. ve Samur, R. (2021). Yiyecek içecek işletmelerinde çalş̧anların yönetici koçluk davranışı algısının iş tatmini üzerindeki etkisi. Manas Sosyal Araștrmalar Dergisi, 10(1), 608-618.

Geliş Tarihi / Received Date: 30.09.2020

Kabul Tarihi / Accepted Date: 24.11.2020

\footnotetext{
${ }^{1}$ Dr. Öğr. Üyesi, Selçuk Üniversitesi, Beyşehir Ali Akkanat İşletme Fakültesi, erhankilinc@selcuk.edu.tr

(iD) ORCID: 0000-0002-2065-2407

2 Dr. Öğr. Üyesi, Konya Selçuk Üniversitesi, Turizm Fakültesi, fvarol@selcuk.edu.tr

(iD ORCID: 0000-0002-0258-5220

${ }^{3}$ Lisans Öğrencisi, Konya Selçuk Üniversitesi, Beyşehir Ali Akkanat İşletme Fakültesi, rabiasmrr@gmail.com

(iD) ORCID: 0000-0002-4748-7659
} 


\section{Giriş}

Günümüz iş dünyasında işletmeler, rakiplerinden daha iyi performans gösterebilmek ve pazar paylarını artırmak için çeşitli arayışlar içerisindedirler. Bu arayışların temel hedef noktası, işletme performansının geliştirilmesidir. İşletme performansının geliştirilmesi ise, işletmelerin en önemli rekabet avantaj unsuru olan çalışanların performansından ve verimliliğinin artırılması ile mümkündür. Bu noktada modern işletme bilimleri, çalısanlarını güçlendirmenin onların verimliliğini artırılmasında oldukça önemli bir unsur olduğunu ortaya koymaktadırlar. Bu anlayışa göre; çalışanlar işyerlerinde kendi işlerinin kontrollerini ele aldıklarında ve karar verme yetkisine sahip olduklarında, daha güvenli, daha yetenekli, daha etkin ve verimli çalışmaktadırlar. Bu durum onların iş tatminlerini, iş performanslarını ve dolayısıyla işletmenin performansını artırmaktadır.

Diğer taraftan yüksek performans beklentisi içerisindeki yöneticiler ve işgörenler, işlerini yürütürken zaman zaman desteğe, görüş alışverişinde bulunmaya ve fikir almaya (danışmaya) ihtiyaçları bulunmaktadır. İşletmeler, deneyimli yöneticileri kullanarak bu desteği yöneticilerine ve çalışanlarına sağlayabilirler. Yönetim biliminde koçluk (mentorluk) adı verilen bu kavram bazen bir meslek, bazen bir strateji ve bazense bir eğitim olarak değerlendirildiği görülmektedir. Günümüzde koçluk davranışı, özellikle örgütlerde koçluk davranışı, hakkında yeterince ampirik çalışmanın olmadığı görülmektedir.

Koçluk, bireylerin veya ekiplerin yetkinlik, yeterlilik, karar verme, yaşam kalitesini arttırma ve kendileri için hedef belirlemelerinde karşılarına çıkacak seçenekleri değerlendirmeleri için çeşitli ve farklı yollar görmelerine ve denemelerine yardımcı olan bir uzmanlık alanı olarak tanımlanmaktadır. Bir koçluk iliş̧kisinde, bireylerin içgörülerini geliştirmek ve yeni fikir ve davranışları denemeleri için onların güçlü yönlerine ve deneyimlerine odaklanmak söz konusudur.

Yönetici koçluğu (ExecutiveCoaching), çalışanlarını geliştirmek isteyen kuruluşlar için son zamanlarda hizla popüler hale gelen bir kavramdır (Kampa-Kokesch ve Anderson, 2001; Feldman ve Lankau, 2005). Yönetici koçluğu sayesinde kişinin iş hayatındaki zorluklarla mücadele etmesi kolaylaşmakta ve bu durum çalışanın iş tatminini olumlu etkilemektedir (Gezer, 2016, s. 61-62). Ancak, birçok işletme, koçluk sürecini yönetmek ve sonuçları ölçmek için disiplinli bir yaklaşımdan yoksundur (McDermott, 2007, s. 35). Ayrıca yönetici koçluk, son 10 yılda hızla büyümesine rağmen diğer koçluk formlarında da olduğu gibi yönetim koçluğunun en önemli zayıf yönlerinden birisi bu koçluğun bireysel ve/veya örgütsel öğrenme ve performans üzerindeki etkisini gösteren ampirik kantların olmamasıdır (Hagen, 2012). Feldman ve Lankau'a göre (2005, s. 830), işletmenin ve yönetimsel rollerin dinamik doğasına rağmen, koçluk üzerine akademik araştırma, uygulayıcı literatürünün çok gerisinde kalmıştır. Bu anlamda yönetici koçluk davranışı üzerinde yapılmış bu çalıșma, alanyazındaki bu eksikliğin giderilmesine katkı yapmayı amaçlamaktadır.

Ellinger (2003) tarafindan dağıtım sektöründe yapılan bir incelemede, yönetimsel koçluğun sonuçları deneysel olarak analiz edilmiştir. Elde edilen sonuçlara göre yönetici koçluğu davranışları, çalışanların iş memnuniyeti ve yaptıkları işteki performanslarını olumlu yönde etkilediği saptanmıştır. Gezer'e göre (2016,s. 61-62), yönetici koçluğu çalışanların iş hayatındaki zorluklar ve engellerle mücadele etmesi kolaylaşmakta ve çalşşanın iş tatminini artırmaktadır. ICF (Uluslararası Koçluk Federasyonu) (2012) tarafindan yapılan bir araştırmada, katılımcıların \%93'ü koçluğun iş tatmini konusuna çok önemli bir etkisi olduğunu belirtmişlerdir (Kalkavan, 2015, s. 100).

Park (2007) tarafindan bir teknoloji şirketinde 187 çalışan üzerinde yapılan bir araştırmada, yönetici koçluğunun çalışanlar üzerindeki etkisi incelenmiştir. Araştırma sonuçlarına göre, yönetici koçluğunun işgörenlerin kişisel öğrenmeleri ve örgüte bağllıklarını olumlu yönde etkilediği sonuca varılmıştır. Natale ve Diamante (2005), organizasyonlar için koçluğun sayısız olumlu faydalarını tanımlamaktadır. Bunlar; kişisel ve mesleki hedeflere ulaşılması, satışların artması, çalışanların memnuniyetinin artması, daha iyi organizasyonel iletişim, daha fazla öz bilgi, daha etkili değişim sağlama yeteneği ve daha hızlı yapma kapasitesi ve daha iyi kararlardır. Kombarakaran, Yang, Baker ve Fernandes (2008) çalışmalarında, koçluk uygulamalarının işletmelerde olumlu sonuçlar verdiğini, liderlik becerilerini çeşitli şekillerde geliştirdiğini ve yöneticilerin işletmeleri başarılı bir şekilde yönetebilmeleri için yönetici koçluk davranışının gerekliliğini ortaya koymuşlardır.

Bu çalışma, işletmelerde yönetici koçluk davranışı kavramının çalışanların iş tatmini üzerindeki etkisini ölçmeyi amaçlamaktadır. Bu kapsamda, Konya ilinde faaliyet gösteren kafelerde çalışanlar üzerinde anket uygulaması yapılmış, sosyo-demografik değişkenleri (cinsiyet, medeni durum, yaş, eğitim durumu ve 
meslek) açısından yönetici koçluk davranışı ve iş tatmininin farklılık gösterip göstermediği de ortaya konmaya çalışılımıştır. Alanyazında, yönetici koçluk davranışı üzerine yapılan ampirik çalışma sayısının az sayıda olması, bu konuda yapılacak çalışmalara ihtiyaç olduğunu göstermektedir. Ayrıca kafe gibi aktif işleyen ve emek yoğun işletmelerde, yönetici koçluk davranışının çalısanların iş tatminleri üzerindeki etkisinin ortaya konulması, bu sektörde hizmet kalitesinin artırlmasında katkı sağlayacaktır. Araştırma sonucunda ulaşılan bulguların konuyla ilgili literatüre katkısı yanı sıra, ilerde yapılacak benzer ölçüm çalışmalarına da yararlı olacağı düşünülmektedir.

\section{Kavramsal Çerçeve}

\section{Koçluk ve Yönetici Koçluk Davranışı}

Koçluk kavramı; öğretmek, eğitmek, danışmanlık yapmak, bilgi vermek, yol göstermek, yöneltmek gibi kelime anlamlara gelmektedir (Çelik, Akatay ve Şimşek, 2007, s. 218). Koçluk TDK'da, "Kişilerin liderlik veya yöneticilik özelliklerini, becerilerini geliştirmeye yönelik, belli bir amacı hedefleyerek daha etkili sonuçlara ulaşmasını sağlamak üzere verilen hizmet" olarak açıklanmıştır (http://tdk.gov.tr/). Witherspoon ve White'a (1996) göre, koç kelimesi ilk olarak 1500'lerde İngilizce olarak kullanılmıştır. Zamanla spor dünyasına daha sonra da iş dünyasında kullanılmaya başlanılan koçluk kavramın bir meslek olarak kullanılmaya başlanması 1980’li yılları bulmuştur (Çelik vd., 2007, s. 217).

İnsan kaynakları terimler ansiklopedik sözlüğünde koçluk, “İşletmede çalışan bir kişiyi motive etmek, korumak, becerilerini geliştirmek, şahsiyetlerini güçlendirmek ve geri bildirim sağlamakla görevlendirilmiş, konusunda uzman ve tecrübeli bir kişi veya olgun, bilgili, şahsiyetli, ahlaklı bir işçi, meslektaş veya yönetici"” şeklinde tanımlamıştır (Seyyar ve Öz, 2007, s. 242). Witherspoon ve White (1996), koçluğu "etkili eylem, performans sağlamak için tasarlanmış gizli, son derece kişisel bir öğrenme süreci” olarak tanımlamıştır. Koçluk, insanların kendi performanslarını en üst düzeye ulaşmaları için kapasitelerini ortaya çıkarmaktır. Onlara öğretmek yerine kendilerinin öğrenmelerine imkân vermektir (Whitmore, 2017, s. 29). Çünkü ister kişisel ister işle ilgili olsun davranış değişikliğinin başarısı, kişinin başlangıçtaki kendini tanıma ve değişmeye hazır olma düzeyi ile ilgilidir (Nowack, 1999).

Alanyazında, koçluk kavramının geniş bir yelpazede kullanıldığı görülmektedir. Hamlin, Ellinger ve Beattie (2008), bu konuda kapsamlı bir alanyazın taraması yapmış ve 37 koçluk tanımı saptamıştır. Çeşitli alanyazında araştırmacılar, koçluk kavramının farklı türlerinin tanımlarının, amaçlarının ve süreçlerinin bir analizine dayanarak, "koçluk", "yönetici koçluğu" "iş koçluğu” ve "yaşam koçluğu” olmak üzere dört ana başlik altında toplamışlardır.

İşletmelerde koçlar, genç yöneticilerin "liderlik tarzlarını", "karar alma ve problem çözme tekniklerini”, "başarılı bir ekip oluşturmasını", "iyi bir iletişim ve ilişsi kurmasını", "örgütte oluşabilecek çatışmaları yönetebilmesini", "çalışanların performanslarını değerlendirebilmesini”, "çalışanları motive etmeyi", "delege etme ve duygusal zekâsını kullanmayı" ve "geliştirme” gibi konularda bilgi ve beceri kazanması için onlara rehberlik eden kişilerdir (Barutçugil, 2018, s. 53). Witherspoon ve White'a göre (1996), koç, seçenekleri belirleyen, zorlukları ortaya çıkaran ve alternatif davranışlar başlatan kişidir. Feldman ve Lankau’yagöre (2005), yönetici koçluğu uygulaması, kuruluşlar tarafindan lider bir geliştirme stratejisi olarak yaygın bir şekilde benimsenmiştir.

Harvard Business Review'deki makalelerinde Sherman ve Freas (2004, s. 82-83), yönetici koçluğunu "geçmişin Vahşi Batı'sı gibi, sınırları kaotik, büyük ölçüde keşfedilmemiş ve riskle doludur, ancak bununla beraber son derece umut vericidir” şeklinde ifade etmiştir. Onlara göre iyi bir koç; entelektüel bağımsızlık, akıl yürütme ve problem çözme kapasitesi oluşturmalarına ve karmaşık çalışma ortamlarını idare edebilmelerine yardımcı olarak çalışanları daha anlamlı bir şekilde konumlandırabilir. Buna karşılık, iyi bir koç kişisel geri bildirime açıktır, sürekli öğrenir ve daha iyi bir koç olarak değişmeye isteklidir (Sherman ve Freas, 2004).

Killburg'a göre (2000, s. 65), yönetici koçluğu, "bir kuruluşta yönetici yetkisi ve sorumluluğu olan bir kişi ile çalışanın performans ve memnuniyetinin iyileştirilmesine yönelik, karşılıklı olarak belirlenmiş bir dizi hedefe ulaşmasına yardımcı olmak amacıyla çeşitli davranış teknikleri kullanan bir danışman arasında kurulan yardım ilişkisidir". Peltier'e göre (2011), iyi bilgilendirilmiş bir koç, etkili planların gerçekleştirilmesi ve takip edilmesi için kısa ve uzun vadeli hedefler belirler. Planların koç tarafindan açıkça tanınması ve benimsenmesi gerekmektedir. Yönetici koçluğu, kısa ve uzun vadeli hedeflere ulaşma becerisi sergilemede, deneyime dayalı bir geliştirme sürecidir. Yönetici koçun kendi içgörüleri ve gözlemleriyle, bireyler kendi güçlü yönlerinin daha fazla farkına varır ve hedefe ulaşmak için strateji ve planlar geliştirirler. 
Burada koçun rolü, kararlaştırılan hedefe ulaşmak hususunda tarafsız ve nesnel bir stratejik ortak olmasıdır (Barutçu ve Özbay, 2009, s. 50).

Yönetici koçluk davranışı, iş hayatındaki yöneticilerin özel yaşamlarının yanı sıra çalışma hayatlarıyla da ilgili yaşadıkları problemlerin çözümüne dair yöneldikleri koçluk kavramıdır. Yönetici koçluğunun insan kaynakları geliştirme uygulaması, son yıllarda olumlu sonuçlarla belirgin bir şekilde artmıştır. Koçluğun öz farkındalığı artırdığı, anlayışı artırdığı ve sürekli davranış değ̆işikliğini geliş̧irdiği bulunmuştur (Wasylyshyn, 2003). Kilburg'un (1996) dairesel modeline göre kuruluşların, koçluğun kurumun öğrenme ve gelişim gündemine nasıl uyacağı hususunda, genel bir bakış açısına sahip olmaları gerekmektedir. Ayrıca yöneticilerin kendileri adına lider olarak açık oldukları bir öğrenme kültürü geliştirmeleri ve daha fazla öz farkındalık kazanmalarına yardımcı olacak statükoyu sorgulama düzeyine geçmeleri gerekir.

Bazı yöneticiler belirli becerileri öğrenmek için koçluğu kullanırken, diğerleri ise işteki performansı arttırmak ve iş veya profesyonel yaşamdaki ilerlemeye hazırlanmak için kullanır (Witherspoon ve White, 1996). Yönetici koçluğu, yöneticilerin kişisel ve mesleki büyümelerini teşvik ederek ve doğrudan dönüşümlü öğrenme sağlayarak davranış biçimlerini etkileyen, böylelikle çalışanlarının davranışlarını ve performansını etkileyebilen bir yöntemdir. Yönetici eğitim ve geliştirme yönteminin temel amac1, yöneticilerin işlerinde davranış biçimlerindeki değişimi olumlu yönde teşvik etmektir (Lewis-Duarte ve Bligh, 2012). Yönetici koçluğu, liderlik davranışında sürekli değişiklik sağlamayı amaçlayan işbirliğine dayalı, bireyselleştirilmiş bir ilişsi içermektedir. Yeni olumlu davranışlar uygulandıkça, sürekli öğrenme, destek, teşvik ve geri bildirim sağlamaktadır (Tobias, 1996).

\section{İş Tatmini}

Alanyazın incelendiğinde iş tatmini; çalışanların öncelikle yaptı̆̆ işten, işyerinden, iş çevresinden, yöneticilerinden, birlikte çalıştığı ekipten ve genel olarak örgütten elde etmeye çalıştığı, rahatlatıcı ve huzur verici bir duygu olarak tanımlanmaktadır (Akınc1, 2002; Çarıkçı, 2000; Karaduman, 2002, s. 70). İş tatmini, örgütlerde bağlllık, iş kalitesi ve performansın artmasından, işten ayrılma, stres ve tükenmişliğin azalmasına kadar birçok olumlu katkı sağlayan bir kavramdır. Örgütlerde iş tatminsizliği ise, geç gelme, verimsizlik ve işten ayrılma gibi örgüt açısından maliyetli sonuçlara neden olabilmektedir. İşs tatmini, motivasyonda olduğu gibi içsel ve dişsal nedenlerden sağlanabilmektedir (Akınc1, 2002; Çarıkçı, 2000; Üçüncü, 2016, s. 11). İş tatminin en önemli özelliklerinden birisi, zihinsel olmaktan çok duygusal bir kavram olmasıdır. Tatmin olma duygusu, ancak birey tarafindan hissedilebilir ve onun iç huzura ulaşmasına katkı sağlayacağı bir rol üstlenebilir (İşcan ve Timuroğlu, 2007).

Yöneticilik koçluk davranışı, literatürde yakın zamanda önem kazanan bir kavram olması nedeniyle bu kavram üzerine yapılan çalışmaları sayıca az ve kısıtlıdır. Yapılan çalışmalar incelendiğinde, işletmelerde yönetici koçluk davranışlarının çalışanların iş tatmini üzerinde olumlu yönde önemli etkilerinin olduğunu görülmektedir (Ellinger, 2013; Gezer, 2016; Kalkavan, 2015;Natale ve Diamante, 2005; Park, 2007).

Araştırmanın amacı kapsamında aşağıdaki hipotezler türetilmiştir. "Kafe işletmelerinde yönetici koçluk davranışının çalışanların iş tatmini üzerinde bir etkisinin var mıdır? varsa bu etki ne düzeydedir?" sorularına cevap aranmıştır.

$\mathrm{H}_{1}$ : Kafe çalışanlarının yönetici koçluk davranışı algılarının iş tatmini düzeyi üzerinde istatistiksel olarak anlamlı bir etkisi vardır.

$\mathrm{H}_{2.1}$ : Cinsiyet değişkeni bakımından kafe çalışanlarının yönetici koçluk davranışlarına ilişkin istatistiksel olarak anlamlı bir farklılık vardır.

$\mathrm{H}_{2.2}$ : Cinsiyet değişkeni bakımından kafe çalışanlarının iş tatmini düzeyine ilişkin istatistiksel olarak anlamlı bir farklilik vardır.

$\mathrm{H}_{3.1}$ : Medeni durum değişkeni bakımından kafe çalışanlarının yönetici koçluk davranışlarına ilişkin istatistiksel olarak anlamlı bir farklılık vardır.

$\mathrm{H}_{3.2}$ : Medeni durum değişkeni bakımından kafe çalışanlarının iş tatmini düzeyine ilişkin istatistiksel olarak anlamlı bir farklılık vardır.

$\mathrm{H}_{4.1}$ : Yaş değişkeni bakımından kafe çalışanlarının yönetici koçluk davranışlarına ilişkin istatistiksel olarak anlamlı bir farklılik vardır. 
$\mathrm{H}_{4.2}$ : Yaş değişkeni bakımından kafe çalışanlarının iş tatmini düzeyine ilişkin istatistiksel olarak anlamlı bir farklılık vardir.

$\mathrm{H}_{5.1}$ : Eğitim durumu değişkeni bakımından kafe çalışanlarının yönetici koçluk davranışlarına ilişkin istatistiksel olarak anlamlı bir farklılık vardir.

$\mathrm{H}_{5.2:}$ Eğitim durumu değişkeni bakımından kafe çalışanlarının iş tatmini düzeyine ilişkin istatistiksel olarak anlamlı bir farklilik vardır.

$\mathrm{H}_{6.1}$ : Meslek değişkeni bakımından kafe çalışanlarının yönetici koçluk davranışlarına ilişkin istatistiksel olarak anlamlı bir farklılık vardır.

$\mathrm{H}_{6.2}$ : Meslek değişkeni bakımından kafe çalışanlarının iş tatmini düzeyine ilişkin istatistiksel olarak anlamlı bir farklılık vardır.

\section{Yöntem}

Bu çalışma, tanımlayıcı ve kesitsel bir araştırmadır. Araştırmada, kolayda ve basit rastgele örnekleme tekniği ile yüz yüze anket yöntemi tercih edilmiştir. Araştırma, Konya ilinde faaliyet gösteren kafelerde görev yapan 100 personel üzerinde gerçekleştirilmiştir. Orijinal yazımıyla Fransızca "café" olan kafe, müşterilerine basit yiyeceklerin ve her türlü sıcak-soğuk içeceğin servis edildiği, genellikle kısıtlı bir menüye sahip olan, insanların bir araya gelip zamanlarını geçirdikleri sosyal mekânlar ve küçük işletmelerdir. Araştırmanın verileri, 2019 yll Şubat ayı içerisinde toplanmıştır.

\section{Veri Toplama Araçları}

Araştırmada veri toplamak için kullanılan anket formu, 7'si sosyo-demografik soru olmak üzere toplam 34 sorudan oluşmaktadır. Araştırmada kullanılan Koçluk davranışı ölçeği, Ellinger ve Keller tarafindan 2003 yllında geliştirilen "Yönetici Koçluk Davranışı Ölçeği”nde yer alan 7 sorudan oluşmaktadır. Bu ölçek, Gezer ve Atan (2016) tarafindan giyim sektöründe yapılan çalışmada kullanılmıştır. İş tatmini için 20 sorudan oluşan "Minnesota İş Tatmini Ölçeği" kullanılmıştır. Araştırma ölçekleri 5'li Likert şeklinde düzenlenmiştir.

Anketin güvenirliği, iç tutarllık katsayıları değerlendirilerek her ölçek için ayrıca hesaplanmıştır. Alpar'a göre (2000), anketin güvenilirliğinin test edilmesinde kullanılan Cronbach Alfa güvenilirlik katsayısı 60-79 arasında olduğunda oldukça güvenilir, 80-100 arasında olduğunda ise ölçek yüksek güvenilirlikte kabul edilmektedir. Yönetici Koçluk Davranışı Ölçeğinin geçerlilik güvenirlik katsayısı 0,806 iken; Minnesota İş Tatmini Ölçeğininki 0,916 olarak saptanmıştır. Bu sayılar, ölçeklerin yüksek güvenilirlikte olduğu göstermektedir.

\section{Verilerin Analizi}

Yapılan normal dağılım analizi sonucunda, işkoliklik, yenilikçi iş anlayışı ve iş tatmini ölçeklerinde verilerin normal dağılmadığı $(\mathrm{p}<0,005)$ saptanmıştır. Normal dağılımın diğer varsayımları olan ortalamamedyanın birbirine yakınlığı ile basıklık (kurtosis) ve çarpıklı̆̆ı (skewnes) $-2,+2$ arasında olması gerekliliği açısından incelendiğinde; değişkene göre bu değerlerin normal dağllıma uyduğu görülmüştür. Bu nedenle verilerin analizinde hem parametrik hem de parametrik olmayan testlerin kullanılmasına karar verilmiştir. Veriler, yüzde ve frekanslar, t-testi ve regresyon analizi testleri ile elde edilerek, ortaya çıkan bulgular yorumlanmıştır. Bununla birlikte, çoklu sosyo-demografik değişkenlerde grup başına düşen ölçüm sayısı bazı gruplarda 30'un altında olduğundan, parametrik olmayan testlerden Kruskal-Wallis testinden yararlanılmıştır. Veriler SPSS 22.0 (Statistical PackageforSocialSciences) paket programında değerlendirilmiştir.

\section{Bulgular}

Araştırma anketlerinden elde edilen bulgular aşağıda verilmiştir. Araştırmaya katılanların sosyodemografik olarak incelendiğinde; katılımcıların \%59'unun kadın, \%69'unun bekar, \%36'sının lise mezunu, \%42'sinin garson/kasiyer/ komi; \%45’inin 18-25 yaş aralığında; \%34’ünün kurumda çalışma süresi 4-6 yıl arası olduğu saptanmışır (Tablo 1). 
Tablo 1. Kattlimolarn Sosyo-Demografik Özelliklere Göre Dağzllmı

\begin{tabular}{|c|c|c|c|}
\hline \multicolumn{2}{|c|}{ Sosyo-Demografik Özellikler } & \multirow{2}{*}{$\frac{\text { Say1 (n) }}{59}$} & \multirow{2}{*}{$\frac{\text { Yüzde (\%) }}{59}$} \\
\hline & Kadın & & \\
\hline Cinsiyet & Erkek & 41 & 41 \\
\hline \multirow{2}{*}{$\begin{array}{l}\text { Medeni } \\
\text { durum }\end{array}$} & Evli & 31 & 31 \\
\hline & Bekâr & 69 & 69 \\
\hline \multirow{4}{*}{$\begin{array}{l}\text { Eğitim } \\
\text { durumu }\end{array}$} & İlköğretim & 13 & 13 \\
\hline & Lise & 36 & 36 \\
\hline & Ön lisans & 24 & 24 \\
\hline & Lisans & 27 & 27 \\
\hline \multirow{3}{*}{ Meslek } & İşletme yöneticisi/ yardımcısı & 26 & 26 \\
\hline & Garson/komi/ kasiyer & 42 & 42 \\
\hline & Yardımcı hizmetler & 32 & 32 \\
\hline \multirow{3}{*}{ Yaş durumu } & $18-25$ yaş & 45 & 45 \\
\hline & $26-35$ yaş & 35 & 35 \\
\hline & 36 yaş ve üzeri & 20 & 20 \\
\hline \multirow{4}{*}{$\begin{array}{l}\text { Kurumda } \\
\text { çalışma süresi }\end{array}$} & $0-3$ yil arası & 25 & 25 \\
\hline & 4-6 yil arasi & 34 & 34 \\
\hline & $7-10 \mathrm{yll}$ & 17 & 17 \\
\hline & 11 yll ve üzeri & 24 & 24 \\
\hline \multicolumn{2}{|l|}{ Toplam } & 100 & 100,0 \\
\hline
\end{tabular}

Tablo 2'de regresyon analizi sonuçlarına göre çalışanların yönetici koçluk davranışı algılarının iş tatmini üzerinde pozitif ve anlamlı bir etkiye sahip olduğu görülmektedir $(\beta=-0,451 \quad \mathrm{p}<0,001)$. R2 değerinin 0,195 olması, yönetici koçluk davranışının iş tatminin \%19,5'lik kısmını açıladığını göstermektedir. Bu sonuca göre $\mathrm{H}_{1}$ hipotezi kabul edilmiştir.

Tablo 2. Katılımolarn Yönetici Koçluk Davranışı Düreyi Algolarmm Iș̣ Tatmini Üžrindeki Etkisine İlişkin Regresyon Analizi

\begin{tabular}{cccccc}
\hline $\mathbf{R}$ & $\mathbf{R} 2$ & Düzeltilmiş R2 & $\mathbf{F}$ & $\boldsymbol{\beta}$ & $\mathbf{p}$ \\
\hline 0,451 & 0,203 & 0,195 & 25,005 & 0,451 & 0,000 \\
\hline
\end{tabular}

Bağımlı Değişken: Yönetici koçluk davranışı

Bağımsız Değişken: İş tatmini

Katılımcıların verdikleri cevaplar doğrultusunda, yöneticilerinin koçluk davranışı için en çok "Yöneticim, işimi daha iyi yapabilmem için tüm gerekli kaynakları tedarik eder" ve "Yöneticim benimle birlikte beklentileri belirler ve bu beklentilerin, kurumun hedeflerini genişletmedeki önemini bana anlatır" yargılarına, en az "Yöneticim, öğrenmeme yardımcı olmak için analojiler, senaryolar ve örnekler kullanır" yargısına katıldıkları saptanmıştır. Çalışanlarının iş tatmini açısından içsel iş tatmini dışsal iş tatmininden daha yüksek olduğu görülmektedir (Tablo 3).

Tablo 3. Araștırma Ölçekleri Faktörleri Açısından Puan Ortalamaların Dağ̀llmu (n=100)

\begin{tabular}{lcccc}
\hline Yönetici Koçluk Davranışı & Min. & $\begin{array}{c}\text { Max. } \\
\text { Ort. }\end{array}$ & $\begin{array}{c}\text { Standart } \\
\text { Hata }\end{array}$ \\
\hline Yöneticim, işimi daha iyi yapabilmem için tüm gerekli kaynakları tedarik eder. & 1 & 5 & 3,7500 & 1,11351 \\
\hline $\begin{array}{l}\text { Yöneticim benimle birlikte beklentileri belirler ve bu beklentilerin, kurumun } \\
\text { hedeflerini genişletmedeki önemini bana anlatır. }\end{array}$ & 1 & 5 & 3,6100 &, 97333 \\
\hline $\begin{array}{l}\text { Olayları ayrıntılarıyla düşünmeme yardımc1 olmak için yöneticim, çözüm } \\
\text { üretmektense bana sorular sorar. }\end{array}$ & 1 & 5 & 3,5400 & 1,10481 \\
\hline $\begin{array}{l}\text { Yöneticim, etkileşimlerin bana fayda sağladığından emin olmak için benden de geri } \\
\text { bildirim ister. }\end{array}$ & 1 & 5 & 3,5100 & 1,19337 \\
\hline $\begin{array}{l}\text { Yöneticim, büyük resmi görmeme yardım ederek bakış açımı genişletmem için } \\
\text { beni teşvik eder. }\end{array}$ & 1 & 5 & 3,5000 & 1,02000 \\
\hline Yöneticim bana yapıcı nitelikte geri bildirim verir. & 1 & 5 & 3,4200 & 1,10261 \\
\hline $\begin{array}{l}\text { Yöneticim, öğrenmeme yardımcı olmak için analojiler, senaryolar ve örnekler } \\
\text { kullanır. }\end{array}$ & 1 & 5 & 3,1700 & 1,22314 \\
\hline Toplam Yönetici Koçluk Düzeyi & 1 & 5 & $\mathbf{3 , 5 0 0 0}$ & $\mathbf{0 , 7 5 3 0 6}$ \\
\hline İçsel iş tatmini & 1 & 5 & 3,8940 & 0,67955 \\
\hline Dişsal iş tatmini & 1 & 5 & 3,6971 & 0,69045 \\
\hline Toplam İş Tatmini & $\mathbf{1}$ & $\mathbf{5}$ & $\mathbf{3 , 7 9 5 6}$ & $\mathbf{0 , 6 2 2 2 9}$ \\
\hline
\end{tabular}


Tablo 4'te bazı sosyo-demografik değişkenlere (cinsiyet ve medeni durum) göre araştırma ölçeklerine verilen cevapların $\mathrm{t}$ testi analizi incelendiğinde;

- Cinsiyet değişkeni bakımından yönetici koçluk düzeyi ile iş tatmini arasında istatistiksel olarak anlamlı bir farklılık olmadığ $1(\mathrm{p}>0,05)\left(\mathrm{H}_{2.1} \mathrm{ve}_{2.2}\right.$ hipotezleri reddedilmiştir);

- Medeni durum değişkeni bakımından yönetici koçluk düzeyi ile iş tatmini arasında istatistiksel olarak anlamlı bir farklılık olmadığı $(\mathrm{p}>0,05)\left(\mathrm{H}_{3.1} \mathrm{ve}_{3.2}\right.$ hipotezleri reddedilmiştir) saptanmıştır.

Tablo 4. Yönetici Koçluk Davramışı ve Callşan İș Tatmini Düzeylerinin Sosyo-Demografik Değğskeenlere Göre Farkhllk Gösterip Göstermedig̈ine Illiskkin Student T Testi Analiz̨i

\begin{tabular}{|c|c|c|c|c|c|c|c|}
\hline Değişker & & $\begin{array}{l}\text { Değişken Alt } \\
\text { Boyutları }\end{array}$ & $\mathbf{N}$ & Ort. & $\begin{array}{c}\text { Standart } \\
\text { Hata }\end{array}$ & $\bar{t}$ & $\mathrm{p}$ \\
\hline \multirow{4}{*}{ Cinsiyet } & \multirow{2}{*}{$\begin{array}{l}\text { Yönetici Koçluk } \\
\text { Davranış1 }\end{array}$} & Erkek & 59 & 3,4310 &, 72770 & \multirow[t]{2}{*}{$-1,100$} & \multirow[t]{2}{*}{0,274} \\
\hline & & Kadın & 41 & 3,5993 & ,78651 & & \\
\hline & \multirow{2}{*}{ İş Tatmini } & Erkek & 59 & 3,7608 & ,64779 & \multirow[t]{2}{*}{$-0,669$} & \multirow[t]{2}{*}{0,505} \\
\hline & & Kadın & 41 & 3,8456 & , 58788 & & \\
\hline \multirow{4}{*}{$\begin{array}{l}\text { Medeni } \\
\text { durum }\end{array}$} & \multirow{2}{*}{$\begin{array}{l}\text { Yönetici Koçluk } \\
\text { Davranış1 }\end{array}$} & Evli & 31 & 3,5576 & 68844 & \multirow[t]{2}{*}{0,511} & \multirow[t]{2}{*}{0,611} \\
\hline & & Bekâr & 69 & 3,4741 & ,78380 & & \\
\hline & \multirow{2}{*}{ İş Tatmini } & Evli & 31 & 3,8894 &, 50654 & \multirow[t]{2}{*}{1,011} & \multirow[t]{2}{*}{0,315} \\
\hline & & Bekâr & 69 & 3,7534 & 66691 & & \\
\hline
\end{tabular}

Tablo 5'te bazı sosyo-demografik değişkenlere (yaş, eğitim durumu ve meslek) göre araştırma ölçeklerine verilen cevapların Kruskal Wallis analizi incelendiğinde;

- Yaş değişskeni bakımından yönetici koçluk düzeyi ile iş tatmini arasında istatistiksel olarak anlamlı bir farklılık olmadığ $(\mathrm{p}>0,05)\left(\mathrm{H}_{4.1}\right.$ ve $\mathrm{H}_{4.2}$ hipotezleri reddedilmiştir);

- Eğitim durumu değisşkeni bakımından yönetici koçluk düzeyi ile iş tatmini arasında istatistiksel olarak anlamlı bir farklılık olmadığı ( $\mathrm{p}>0,05)\left(\mathrm{H}_{5.1}\right.$ ve $\mathrm{H}_{5.2}$ hipotezleri reddedilmiştir);

- Meslek değişseni bakımından yönetici koçluk düzeyi ile iş tatmini arasında istatistiksel olarak anlamlı bir farklılık olmadığı $(\mathrm{p}>0,05)\left(\mathrm{H}_{6.1}\right.$ ve $\mathrm{H}_{6.2}$ hipotezleri reddedilmiştir) saptanmıştır.

Tablo 5. Yönetici Kocluk Davranışı ve Calışan Iss Tatmini Düzeylerinin Sosyo-Demografik Değğskenlere Göre Farklulle Gösterip Göstermediğine Iliskin Kruskal Wallis Analizi

\begin{tabular}{|c|c|c|c|c|c|c|c|}
\hline \multicolumn{2}{|c|}{ Değişken Adı } & Değişken Alt Boyutları & $\mathbf{N}$ & Sira Ort. & sd & $\chi^{2}$ & $\mathrm{p}$ \\
\hline \multirow{6}{*}{$\begin{array}{l}\text { Yaş } \\
\text { durumu }\end{array}$} & Yönetici & $18-25$ yaş & 45 & 50,37 & \multirow{3}{*}{2} & 0,154 & \multirow[t]{3}{*}{0,926} \\
\hline & Koçluk & $26-35$ yaş & 35 & 49,46 & & & \\
\hline & Davranış1 & 36 yaş ve üzeri & 20 & 52,63 & & & \\
\hline & \multirow{3}{*}{ İş Tatmini } & $18-25$ yaş & 45 & 48,18 & \multirow[t]{3}{*}{2} & 1,145 & \multirow[t]{3}{*}{0564} \\
\hline & & $26-35$ yaş & 35 & 50,07 & & & \\
\hline & & 36 yaş ve üzeri & 20 & 56,48 & & & \\
\hline \multirow{6}{*}{ Meslek } & \multirow{3}{*}{$\begin{array}{l}\text { Yönetici Koçluk } \\
\text { Davranışı }\end{array}$} & İşletme yöneticisi/ yardımcısı & 26 & 45,79 & \multirow{3}{*}{2} & 0,951 & \multirow[t]{3}{*}{0,622} \\
\hline & & Garson/ komi/ kasiyer & 42 & 51,75 & & & \\
\hline & & Yardımcı hizmetler & 32 & 52,69 & & & \\
\hline & \multirow{3}{*}{ İş Tatmini } & İşletme yöneticisi/ yardımcısı & 26 & 57,92 & \multirow[t]{3}{*}{2} & 4,789 & \multirow[t]{3}{*}{0,091} \\
\hline & & Garson/ komi/ kasiyer & 42 & 43,25 & & & \\
\hline & & Yardımcı hizmetler & 32 & 53,98 & & & \\
\hline \multirow{8}{*}{$\begin{array}{l}\text { Eğitim } \\
\text { Durumu }\end{array}$} & \multirow{4}{*}{$\begin{array}{l}\text { Yönetici Koçluk } \\
\text { Davranışı }\end{array}$} & İlköğretim & 13 & 43,58 & \multirow[t]{4}{*}{3} & 1,417 & \multirow[t]{4}{*}{0,701} \\
\hline & & Lise & 36 & 53,67 & & & \\
\hline & & Önlisans & 24 & 52,08 & & & \\
\hline & & Lisans & 27 & 48,20 & & & \\
\hline & \multirow{4}{*}{ İş Tatmini } & İlköğretim & 13 & 43,85 & \multirow[t]{4}{*}{3} & 2,721 & \multirow[t]{4}{*}{0,437} \\
\hline & & Lise & 36 & 56,44 & & & \\
\hline & & Önlisans & 24 & 49,65 & & & \\
\hline & & Lisans & 27 & 46,54 & & & \\
\hline
\end{tabular}

\section{Tartışma, Sonuç ve Öneriler}

Günümüzde işletmelerin, iş görenlerinin yaratıcı ve yenilikçi özelliklerini ortaya koymalarına, geçmişe oranla daha fazla gereksinimleri olmaktadır. Bunu sağlamanın en önemli yöntemlerinden biri de onları yönlendirecek, yol gösterecek ve onlara tarafsız yaklaşacak yönetici koçlarıdır. Araştırmalar, çalışanların işte güçlendiklerini hissettiklerinde, daha yüksek iş performansı ortaya koyduklarını, iş tatmini ve organizasyona bağlılık duygularını artırdıklarını göstermektedir. Günümüzde çalışanların, işletme yönetim 
süreçlerine katılımlarını sağlamanın, onlara yetki vermenin, ekip çalışmasını geliştirmenin ve karar süreçlerini artırmanın, kendi rollerini belirlemelerine, anlamlı işler yapmalarına ve işletme kararlarının iyileştirilmesine katkı sağladıkları hususunda genel kabul görmüş bir bakış açısı bulunmaktadır.

Yöneticilerin koçluk davranışlarının, çalı̧anların iş tatminini ne ölçüde etkilediğini belirlemek amacıyla yapılan bu çalışmada, "Kafe işletmelerinde yönetici koçluk davranışının çalışanların iş tatmini üzerinde bir etkisinin var mıdır? varsa bu etki ne düzeydedir?" sorularına cevap aranmıştır. Konya'da faaliyet gösteren kafe işletmeleri çalışanları üzerinde gerçekleştirilen bu araştırmaya, toplamda 100 kafe çalışanı katılmıştır. Araştırma sonuçlarına göre, çalışanların yönetici koçluk davranışı algılarının iş tatmini üzerinde pozitif ve anlamlı bir etkiye sahip olduğu görülmektedir. Yönetici koçluk davranışının iş tatmininin \%19,5'lik kısmını açıkladığını saptanmıştır. Bu durum, yönetici koçluk davranışının çalışanların iş tatmini üzerinde olumlu yönde bir ilişkisi olduğunu ortaya koymaktadır. Ayrıca kafe çalışanlarının, yöneticilik koçluk davranışı

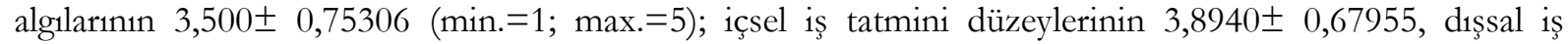
tatmini düzeylerinin 3,6971 $\pm 0,75306$, toplam iş tatmini düzeylerinin $3,7956 \pm 0,62229$ olduğu (min. $=1$; max.=5) saptanmıştır. Ayrıca yapılan analizlere göre sosyo demografik değişkenlerle (cinsiyet, medeni durum, yaş, eğitim durumu ve meslek) göre yönetici koçluk davranışı ile iş tatmininin arasında istatistiksel olarak anlamlı farklılık olmadığı da görülmektedir.

Sonuç olarak hem yapılan alan yazın çalışmaları hem de bu araştırma, işletmelerde yönetici koçluk davranışlarının çalışanların iş tatmini üzerinde etkili olduğunu göstermektedir. Bu çalışmanın bulguları, alan yazında yapılmış çalışmaların (Ellinger, 2013; Gezer, 2016; Kalkavan, 2015; Natale ve Diamante, 2005; Park, 2007) sonuçlarını desteklemektedir. Çalışanların güçlendirilmesi ve optimum seviyede performans gösterebilmeleri için, gerekli araçların, eğitimin, kaynakların, teşvik ve motivasyonun sağlanması gerekmektedir. $\mathrm{Bu}$ durum, çalışanların kendi güçlü yönlerinin daha fazla farkına varmalarına ve gerçek kapasitelerinin ortaya çıkmasına olanak sağlayacaktır. İşletmeler, süreçlerini hızlandırmak ve kaliteli malzeme ve hizmet üretmek için bir yol arıyorsa, çalışanların güçlendirilmesine odaklanmalıdırlar. Bir çalışana, ona güvendiğinizi ve ona zamanında bilgi ve çözümler bulma yetkisi verdiğinizi hissettirebilirseniz, bu çalışan yetkisiz veya önemsiz bir iş yapan bir kişi dahi olsa, sorunların üstesinden daha hızlı bir şekilde gelebilecek ve çözümler sunabilecektir.

Araştırma kapsamında kafe işletmeleri için aşağıdaki önerilerde bulunabilir.

- Kafe işletmeleri çalışanlanına koçluk davranışı kapsamında personel güçlendirme faaliyetleri ile iş tatminleri ve performanslarının artırilması hedeflenebilir

- Çalışanlara işlerinde takdir etme, yetki devretme ve inisiyatif kullanma hakkının sağlanması hem onların iş tatminini artıracak hem de çalışanların olası müşteri sorunları karşısında onların memnuniyetini sağlayacak çözümler üretebilmelerine olanak sağlayacaktır.

- Kafe personelinin çalışma motivasyonlarını güçlendiren ve kapasitelerini artıran eğitim ve teşvik programlar1 uygulanabilir.

Yönetici koçluk davranışının iş görenlerin iş tatmini üzerinde pekiştirici etkisini ortaya koyan bu çalışma, araşıırma maliyet kısıtı nedeniyle sınırlı bir coğrafik alanda yapılmıştır. Ayrıca araştırmaya katılım gönüllük arz ettiğinden ve yiyecek içecek sektöründe iş yoğunluğu yaşandığından, istenilen sayıda katılımcıya ulaşmakta zorluklar yaşanmışır. Bu nedenle, elde edilen bulgulardan bir genelleme yapmak olası değildir. Ayrıca araştırma kapsamına giren hizmet dalları da genişletilebilir. Gelecekte yapılacak araştırmalar için, araştırma kapsamının genişletilerek, farklı örneklemlerde ve ulusal düzeyde hizmet veren işletmelerde yönetici koçluk davranışının farklı örgütsel davranış değişkenleri olan ilişskisinin ve etkisinin incelenmesi, alan yazına katkı sağlaması bakımından önem arz etmektedir.

\section{Etik Beyan}

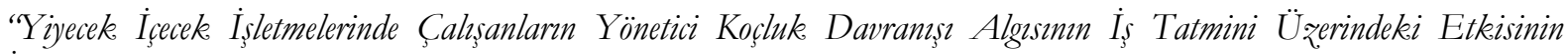
Incelenmesi" başlıklı çalışmanın yazım sürecinde bilimsel kurallara, etik ve alıntı kurallarına uyulmuş; toplanan veriler üzerinde herhangi bir tahrifat yapılmamış ve bu çalışma herhangi başka bir akademik yayın ortamına değerlendirme için gönderilmemiştir. Bu araştırmanın verileri 01.01.2020 tarihinden önce toplandığ1 için etik kurul kararı zorunluluğu taşımamaktadır. 


\section{Kaynakça}

Akıncı, Z. (2002). Turizm sektöründe işgören iş tatminini etkileyen faktörler: beş yıldızlı konaklama işletmelerinde bir uygulama. Akdeniz Üniversitesi İktisadi ve İdari Bilimler Fakültesi Dergisi, 2(4), 1-25.

Alpar, R. (2000). Spor bilimlerinde uygulamal istatistik. Ankara: GSGM Yayınları.

Barutçu, E. ve Özbay, Ö. (2009). Koçluk yaklaşımının yönetici ve iş gören üzerine etkilerine ilişkin bir araştırma. Akademik. Arastermalar ve Calısmalar Dergisi (Akad), 1(1), 47-62.

Barutçugil, İ. (2018). Yönetici için koģluk becerileri. Ankara: Kariyer Yayıncıllk.

Bayram, A., Yıldırım, Y. ve Ergan, S. (2017). Yönetici koçluk davranışı ile içsel pazarlama arasındaki ilişki. III. IBANESS Kongreler Serisi, 71-83.

Çarıkçı, İ. H. (2000). Çalışanların iş tatminlerini etkileyen kişisel özellikler: süpermarket çalışanları üzerinde bir araştırma. Süleyman Demirel Üniversitesi İktisadi İdari Bilimler Fakültesi Dergisi, 5(2), 155-168.

Çelik, A., Akatay, A. ve Şimşek, M. (2007). Kariyer yönetimi ve insan kaynaklar yönetimi uygulamalar. İçinde Şerif Şimşek (Edt). Ankara: Gazi Kitabevi.

Ellinger, A. D. (2013). Supportive supervisors and managerial coaching: exploring their intersections. Journal of Occupational and Organizational Psychology, 86(3), 310-316

Feldman, D. C. ve Lankau, M. J. (2005). Executive coaching: are view and agenda for future research. Journal of Management, 31(6), 829-848.

Gezer, H. (2016). Yönetici koçluk davramısımın çalşsan tatminine etkisi üz̧erine bir araştırma(Yayımlanmamış Yüksek Lisans Tezi). Haliç Üniversitesi Sosyal Bilimler Enstitüsü, İstanbul.

Hagen, M. (2012). Managerial coaching: A review of the literature. Performance Improvement Quarterly, 24(4), 17-39.

Hamlin, R. G., Ellinger, A. E. ve Beattie, R. S. (2008). The emergent "coaching industry": awake-upcall for HRD professionals. Human Resource Development International, 11, 287-305.

İşcan, Ö. F. ve Timuroğlu, M. K. (2007). Örgüt kültürünün iş tatmini üzerindeki etkisi ve bir uygulama. Atatürk Üniversitesi İktisadi ve İdari Bilimler Dergisi, 21(1), 119-135.

Kalkavan, S. (2015). Koçluk etkilediği ve etkilendiği örgütsel faktörler (1. Bask1). İstanbul: Artikel Yayınc1lık.

Kampa-Kokesch, S. ve Anderson, M. (2001). Executive coaching: A comprehensive review of the literature. Consulting Psychology Journal: Practice and Research, 53, 205-228.

Karaduman, A. (2002). Ekip çalışmasinda, liderin iş tatmini üzerindeki etkisi (Yüksek Lisans Tezi). Atatürk Üniversitesi Sosyal Bilimler Enstitüsü, Erzurum.

Kilburg, R. R. (1996). Toward a conceptual understanding and definition of executive coaching. Consulting Psychology Journal: Practice and Research, 48(2), 134.

Kilburg, R. R. (2000). Executive coaching: Developing managerial wisdom in a world of chaos (pp. xiv-253). Washington, DC: American Psychological Association.

Kombarakaran, F. A., Yang, J. A., Baker, M. N. ve Fernandes, P. B. (2008). Executive coaching: It works! Consulting Psychology Journal: Practice and Research, 60(1), 78-90.

Lewis-Duarte, M. ve Bligh, M. (2012). Agents of 'influence': Exploring the usage, timing, and outcomes of executive coaching tactics. Leadership \& Organization Development Journal, 33 (3), 255-281.

McDermott, M., Levenson, A. ve Newton, S. (2007). What coaching can and cannot do for your organization. People and Strategy, 30(2), 30-37.

Natale, S. M. ve Diamante, T. (2005). The five stages of executive coaching: Better process makes better practice. Journal of Business Ethics, 59(4), 361-374.

Nowack, K. M. (1997). Self-ratings as a predictor of assessment center performance. Journal of Social Behavior and Personality, 12, 145-166.

Park, S. (2007). Relationships among managerial coaching in organizations and the outcomes of personal learning, organizational commitment, and turnover intention. Ph.D Thesis, University of Minnesota.

Peltier, B. (2011). The Existential Stance. In The Psychology of Executive Coaching (pp. 196-209). Routledge.

Seyyar A. ve Öz, C. (2007). İnsan kaynaklar terimleri ansiklopedik sö̊lük. İstanbul: Değişim Yayınları.

Sherman, S. ve Freas, A. (2004). The wild west of executive coaching. Harvard Business Review, 82(11), 82-93.

Tobias, L. L. (1996). Coaching executives. Consulting Psychology Journal, 48(2), 87-95.

Üçüncü, K. (2016). İs tatmini ve motivasyon. Karadeniz Teknik Üniversitesi, Fen Bilimleri Enstitüsü, Trabzon.

Wasylyshyn, K. M. (2003). Executive coaching: An outcome study. Consulting Psychology Journal: Practice And Research, 55(2), 94-106

Whitmore, S, J. (2017). Performans için koçluk. 5. Bask1, Ankara: Paloma Yayınevi.

Witherspoon, R. ve White, R. P. (1996). Executive coaching: A continuum of roles. Consulting Psychology Journal: Practiceand Research, 48(2), 124-133. 


\section{EXTENDED ABSTRACT}

Coaching is defined as a field of expertise that helps individuals or teams to see and try various and different ways to evaluate the options they will encounter in competence, competence, decision-making, increasing the quality of life and setting goals for themselves. In a coaching relationship, it is necessary to focus on the strengths and experiences of individuals in order to develop their insights and try out new ideas and behaviors. The concept of coaching means teaching, training, consulting, giving information, guiding, directing (Çelik, Akatay, \& Şimşek, 2007, p. 218).Coaching has been described in the Turkish Language Society (TLS) as "The service provided to improve the leadership or managerial qualities and skills of individuals, to achieve more effective results by targeting a certain purpose" (http://tdk.gov.tr/).According to Witherspoon and White (1996), the word coach was first used in English in the 1500s.In time, the concept of coaching, which was used in the sports world and later in the business world, started to be used as a profession in the 1980s (Çelik, Akatay, \& Şimşek, 2007, p. 217).

When the literature is examined, job satisfaction; It is defined as a comforting and peaceful feeling that employees try to get from their work, workplace, business environment, managers, the team they work with and the organization in general (Karaduman, 2002, p. 70; Çarıkç1, 2000; Akınc1, 2002). Job satisfaction is a concept that makes many positive contributions from the increase of commitment, job quality and performance in organizations to the reduction of job turnover, stress and burnout. One of the most important features of job satisfaction is that it is an emotional concept rather than mental.

This study aims to measure the effect of executive coaching behavior on job satisfaction of employees. In this context, a questionnaire was applied to the employees working in the cafes operating in Konya and it was tried to find out whether executive coaching behavior and job satisfaction differ in terms of socio-demographic variables. This is a descriptive and cross-sectional study. The research was carried out by conducting a survey on 100 employees working in cafes operating in Konya. Cafes are small spaces and small businesses, where people come together and spend their time, often with a limited menu, serving simple foods and all kinds of hot and cold drinks to customers. The study was carried out with face-to-face questionnaire method with cafe employees selected by convenience and simple random sampling technique. Data were collected in February 2019. The research questionnaire consisted of 34 questions, 7 of which were socio-demographic questions. The Coaching Behavior Scale used in the study consists of 7 questions in the "Executive Coaching Behavior Scale El developed by Ellinger and Keller (2003). This scale was also used by Gezer and Atan (2016) in the study conducted in the clothing sector. For job satisfaction, Minnesota Job Satisfaction Scale, which consists of 20 questions, was used. The research scales were arranged as 5-point Likert. The validity and reliability coefficient of the Executive Coaching Behavior Scale was 0.806; The Minnesota Job Satisfaction Scale was found to be 0.916, indicating a high reliability. The research data were evaluated in SPSS package program. Data were interpreted by t-test, Kruskal Wallis test and Regression Analysis tests.

According to the results of the research, it is seen that the employees' perceptions of executive coaching behavior have a positive and significant effect on job satisfaction. It has been determined that executive coaching behavior explains $19.5 \%$ of job satisfaction. This suggests that executive coaching behavior has a positive relationship on the job satisfaction of the employees. In addition, cafe employees' perceptions of management coaching behavior 3,500 $\pm 0,75306$ (min. $=1$; $\max .=5$ ); It was found that the internal job satisfaction level of the employees was 3,8940 $\pm 0,67955$, the external job satisfaction level was 3,6971 $\pm 0,75306$ and the total job satisfaction level was 3,7956 $\pm 0,62229(\min .=1 ; \max .=5)$.

As a result, both literature studies and this study show that executive coaching behaviors in enterprises have positive effect on job satisfaction of employees. The findings of this study support the results of the studies (Ellinger, 2013; Gezer, 2016; Kalkavan, 2015; Natale, \& Diamante, 2005; Park, 2007) conducted in the literature. If the empowerment of employees, the tools, training, resources, incentives and motivations provided to ensure the optimum performance of your employees are provided, they will be made more aware of their own strengths and their real capacity will be revealed. If businesses are looking for a way to accelerate processes and produce quality materials and services, they should focus on empowering employees. If you can make an employee feel that you trust him and empower him to find information and solutions in a timely manner, he or she will be able to solve problems and provide solutions more quickly, even if someone is doing unauthorized or insignificant work. The study, which shows the reinforcing effect of executive coaching on the job satisfaction of the employees, is a guiding feature in the organizations that will put the relationship and effect of this behavior type with other 
behavioral criteria variables and take place in different samples. Within the scope of the research, the following recommendations can be made for cafe businesses:

- Increasing job satisfaction and performance can be targeted with personnel empowerment activities within the scope of coaching behavior of employees of cafe enterprises.

- Providing employees with the right to appreciate, delegate authority and use initiative in their work will enable them to produce solutions that will increase both their job satisfaction and ensure customer satisfaction in the face of possible problems.

- Training and incentive programs that strengthen the working motivation and capacity of cafe staff can be implemented.

For future research, it is important to expand the scope of the research and examine the relationship and effect of executive coaching behavior with different organizational behavior variables in different samples and enterprises serving at national level in terms of contributing to the literature. 